\title{
A Novel Approach to Study the Performance of Finned-Tube Heat Exchangers under Frosting Conditions
}

\author{
A.L. Bendaoud ${ }^{1 \dagger}$, M. Ouzzane ${ }^{2}$, Z. Aidoun ${ }^{2}$ and N. Galanis ${ }^{1}$ \\ ${ }^{l}$ Faculté de Génie, Département de Génie Mécanique, Université de Sherbrooke, \\ 2500, boul. De l'Université, Sherbrooke, JIK 2RI, Québec, Canada. \\ ${ }^{2}$ Ressources Naturelles Canada, \\ 1615 Boulevard Lionel-Boulet CP 4800, Varennes, J3X 1S6, Québec, Canada.
}

$\dagger$ Corresponding Author Email: adlane.bendaoud@usherbrooke.ca

(Received April 25, 2010; accepted March 13, 2011)

\begin{abstract}
Frost accumulation due to moist air flowing on a refrigeration coil cold surface impacts negatively on performance. The frost layer growth has an insulating effect in terms of heat transfer and causes the increase of the air pressure drop by blocking the free flow area across the coil. In this paper a new modeling approach, accounting for heat and mass transfer as well as the hydrodynamics of the problem, is proposed. A related FORTRAN program was developed, allowing the study of a large range of complex refrigerant circuit configurations. This model predicts the dynamic behavior of a refrigeration coil under dry and frosting conditions. Comparisons were made based on the frost mass accumulation and pressure drop across the coil and the results were found to agree reasonably well with experimental results reported in the literature. The model was then applied to study an evaporator typically employed in supermarkets. In terms of refrigerant temperature glide, it was shown that the glide decrease with time because of the decrease of the refrigeration capacity of the coil during the frosting. Further, the air pressure drop is strongly affected by the variation of the free flow area.
\end{abstract}

Keywords: Modeling, Two-phase, Frost, Coil, Mass transfer, Heat transfer, Circuiting, $\mathrm{CO}_{2}$.

\section{NOMENCLATURE}

\begin{tabular}{|c|c|c|c|c|c|}
\hline A & Area & $\left(\mathrm{m}^{2}\right)$ & NF & fin density & $\left(\right.$ fins. $\mathrm{m}^{-1}$ ) \\
\hline $\mathrm{A}_{\mathrm{c}}$ & convective heat transfer area & $\left(\mathrm{m}^{2}\right)$ & NJ & number of junctions & $(-)$ \\
\hline$A_{\min }$ & minimum free flow area & $\left(\mathrm{m}^{2}\right)$ & Nrow & number of rows & $(-)$ \\
\hline $\mathrm{C}_{\mathrm{r}}$ & capacity rate ratio & $(-)$ & NS & number of refrigerant exits & $(-)$ \\
\hline $\mathrm{C}_{\min }$ & minimum thermal capacity rate & $\left(\mathrm{W} \cdot \mathrm{K}^{-1}\right)$ & NT & number of tubes & $(-)$ \\
\hline $\mathrm{C}_{\max }$ & maximum thermal capacity rate & $\left(\mathrm{W} \cdot \mathrm{K}^{-1}\right)$ & NTU & number of heat transfer units & $(-)$ \\
\hline $\mathrm{C}_{\mathrm{p}}$ & $\begin{array}{l}\text { specific heat under constant } \\
\text { pressure }\end{array}$ & $\left(\mathrm{J} \cdot \mathrm{kg}^{-1} \cdot \mathrm{K}^{-1}\right)$ & $\begin{array}{l}\mathrm{P} \\
\operatorname{Pr}\end{array}$ & $\begin{array}{l}\text { pressure } \\
\text { Prandtl number }\end{array}$ & $\begin{array}{l}\left(\mathrm{N} \cdot \mathrm{m}^{-2}\right) \\
(-)\end{array}$ \\
\hline $\mathrm{D}$ & diameter & (m) & $\dot{\mathrm{Q}}$ & heat transfer rate & $(\mathrm{W})$ \\
\hline $\mathrm{D}_{\mathrm{c}}$ & $\begin{array}{l}\text { fin collar outside diameter, } \\
\mathrm{D}_{\mathrm{ou}}+2 \delta_{\text {fin }}\end{array}$ & (m) & $\begin{array}{l}\operatorname{Re} \\
S_{1}\end{array}$ & $\begin{array}{l}\text { Reynolds number } \\
\text { longitudinal tube pitch }\end{array}$ & $\begin{array}{l}(-) \\
(\mathrm{m})\end{array}$ \\
\hline $\mathrm{D}_{\mathrm{v}}$ & diffusion coefficient & $\left(\mathrm{m}^{2} \cdot \mathrm{s}^{-1}\right)$ & $\mathrm{S}_{\mathrm{t}}$ & transversal tube pitch & (m) \\
\hline f & friction factor & $(-)$ & $t$ & time & (s) \\
\hline $\begin{array}{c}\mathrm{F}_{\mathrm{s}} \\
\mathrm{g}\end{array}$ & fin spacing & (m) & $\mathrm{T}, \overline{\mathrm{T}}$ & temperature, mean temperature & $\left({ }^{\circ} \mathrm{C}\right)$ \\
\hline $\mathrm{h}$ & convective heat transfer & $\left(\mathrm{W} \cdot \mathrm{m}^{-2} \cdot \mathrm{K}^{-1}\right)$ & $\begin{array}{l}\mathrm{U} \\
\mathrm{x}\end{array}$ & $\begin{array}{l}\text { overall heat transfer coefficient } \\
\text { quality }\end{array}$ & $\begin{array}{l}\left(\mathrm{W} \cdot \mathrm{m}^{-2} \cdot{ }^{\circ} \mathrm{C}^{-1}\right) \\
(-)\end{array}$ \\
\hline $\mathrm{H}$ & enthalpy & $\left(\mathrm{J}^{\mathrm{kg}}{ }^{-1}\right)$ & $X_{t t}$ & Martinelli parameter & $(-)$ \\
\hline $\mathrm{J}$ & Colburn factor & $(-)$ & $Y_{f}$ & frost layer thickness & (m) \\
\hline $\begin{array}{l}{[\mathrm{J}]} \\
\mathrm{k}\end{array}$ & $\begin{array}{l}\text { matrix of junctions } \\
\text { thermal conductivity }\end{array}$ & $\left(\mathrm{W} \cdot \mathrm{m}^{-1} \cdot{ }^{\circ} \mathrm{C}^{-1}\right)$ & \multicolumn{3}{|c|}{ Greek letters } \\
\hline $\mathrm{L}$ & length & (m) & $\alpha_{f}$ & absorption coefficient & $\left(\mathrm{s}^{-1}\right)$ \\
\hline $\mathrm{m}$ & mass & $(\mathrm{kg})$ & $\rho$ & density & $\left(\mathrm{kg} \cdot \mathrm{m}^{-3}\right)$ \\
\hline$\dot{\mathrm{m}}$ & mass flow rate & $\left(\mathrm{kg} \cdot \mathrm{s}^{-1}\right)$ & $\Delta$ & variation & $(-)$ \\
\hline $\mathrm{NE}$ & number of refrigerant inlets & $(-)$ & $\omega$ & absolute humidity & $(-)$ \\
\hline
\end{tabular}




\begin{tabular}{ll}
$\delta$ & thickness \\
$\theta$ & corrugation angle \\
$\varepsilon$ & effectiveness \\
$\mu$ & dynamic viscosity of fluid \\
$\sigma$ & surface tension \\
$\nu$ & specific volume \\
\multicolumn{2}{l}{ Subscripts } \\
a & air \\
b & bend \\
bc & convective boiling \\
d & dry \\
da & dry air \\
ev & evaporation \\
f & frost, frost layer
\end{tabular}

\section{INTRODUCTION}

Frost formation on heat exchanger surfaces is a common problem in low-temperature applications. When moist air comes into contact with cold heat exchanger surfaces whose temperature is below the freezing point, frosting occurs. The frost layer increases the overall thermal resistance, because it is a porous medium composed by air and ice; when the first layer of frost appears on the heat exchanger surface, it grows continuously, leading to the degradation of heat exchanger performance in terms of lower heat transfer and higher pressure drop. To better understand the thermal and hydrodynamic behaviour of heat exchangers operating under frosting conditions, numerical modeling represents a very cost effective approach to achieve this objective. Several research and development works on heat exchanger coils are available in the literature. Corberan et al. (1998) and Liang et al. (2001) both proposed approaches for thermal analyses of heat exchangers but little detail was given on the problem hydrodynamics and circuiting was limited to simple arrangements. Jiang et al. (2006) proposed CoilDesigner, a design tool in the form of easy to use software, providing a pass by pass analysis of the heat exchanger and calculating mean values of heat transfer coefficients on both air and refrigerant sides. This approximation generally leads to important differences between numerical and experimental results. CoilDesigner does not provide air-side pressure losses which may be important in large refrigeration installations. Ouzzane et al. (2008) and Aidoun et al. (2009) modeled wavy fin refrigeration coils heat using $\mathrm{CO}_{2}$ under dry conditions. The authors used a forward marching technique to solve their conservation equations, based on the discretisation of the quality of the refrigerant. This method is not well adapted to handle complex circuiting situations. Kondepudi et al. (1993a, 1993b) developed an analytical model to predict the performance of finned-tube heat exchangers under frosting conditions. They considered a uniform distribution of frost on the entire heat exchanger external surface and used the ideal gas theory to calculate the mass of water diffused in the frost layer. This model used 50\% ethylene-glycole/water mixture, rather than an evaporating refrigerant, in a single circuit. Seker et al. (2004a, 2004b) performed numerical and experimental investigations of frost formation. The

$\begin{array}{ll}\text { fin } & \text { fin } \\ \mathrm{g} & \text { gas } \\ \text { in } & \text { in, inlet, inner } \\ \mathrm{l} & \text { liquid, linear } \\ \mathrm{lv} & \begin{array}{l}\text { liquid-vapour phase change } \\ \text { property }\end{array} \\ \mathrm{nb} & \text { nucleate boiling } \\ \mathrm{ou} & \text { out, outlet, outer } \\ \mathrm{r} & \text { refrigerant } \\ \mathrm{s} & \text { surface } \\ \mathrm{sat} & \text { saturation } \\ \mathrm{t} & \text { total, tube } \\ \text { tp } & \text { two-phase } \\ \mathrm{V} & \text { vapour } \\ \mathrm{w} & \text { wall, water vapor }\end{array}$

authors used a custom-made heat exchanger and little information on their coil geometry is available. The experiments were performed with a large temperature difference $\left(17{ }^{\circ} \mathrm{C}\right)$ between air and refrigerant. The authors used a correlation for airside heat transfer, based on their own heat exchanger data which cannot be extrapolated to other coil conditions. In this paper, a new, more general coil modeling approach accounting for complex circuiting and frost deposition is proposed. $\mathrm{CO}_{2}$ is the refrigerant flowing through the circuits. The resulting model is built in three parts: the first part handles refrigerant flow in heat exchanger circuits and determines corresponding mass flow by solving the momentum and mass conservation equations. The second part accounts for air-refrigerant heat transfer and pressure drop, based on the e-NTU approach and appropriate correlations. The last part takes care of condensation and frost formation by computing the amount of vapour diffused in the frost layer and the mass directly contributing to increase the frost thickness. Model validation has been performed under dry and frosting conditions. In dry conditions, data obtained from an experimental $\mathrm{CO}_{2}$ secondary refrigeration loop located in CANMETEnergy Laboratories were used (Aidoun et Ouzzane, 2009, and Ouzzane et Aidoun, 2008). In frosting conditions, the data used for validation was gathered from the open literature (Kondepudi et O'Neal, 1993). The model was then applied to study the performance and the operation of an evaporator typically employed in two-door refrigerated supermarket cabinets.

\section{Modeling}

Modeling and simulation are particularly needed for prediction and analysis purposes especially for complex systems such as circuitry in evaporator coils.

The mathematical model described in this paper is restricted to the study of the staggered and finned tube evaporator coils. Subcooled liquid, superheated vapour and two phase flow regimes may occur in these equipments and are therefore incorporated in the model. Two phase flow treatment is based on the homogeneous flow model.

$\mathrm{CO}_{2}$ refrigerant goes through subcooled, evaporation and superheated phases from coil inlet to outlet. The mathematical model developed is based on the following main assumptions: 
- $\quad$ System in quasi steady state conditions

- $\quad$ 1-D flow of refrigerant inside the tube coil.

Gravity forces for both air and refrigerant are neglected.

- $\quad$ Negligible heat losses to the surroundings.

- $\quad$ Uniform air velocity across each tube row.

\subsection{Conservation Equations}

Conservation equations of mass, momentum and energy are successively applied to a control volume element (Fig. 1). The resulting relations are summarized as:

\section{1.a. Conservation Equation of Mass}

$$
\left(\sum \dot{m}_{r}\right)_{o u}=\left(\sum \dot{m}_{r}\right)_{i n} \text { and }\left(\dot{m}_{a}\right)_{o u}=\left(\dot{m}_{a}\right)_{\text {in }}
$$

Pressure losses are calculated in tubes and return bends as follows:

- For tubes :

$\left(P_{r}\right)_{\text {ои }}=\left(P_{r}\right)_{\text {in }}-\left(\Delta P_{r}\right)_{l}$

- For return bends :

$\left(P_{r}\right)_{\text {ou }}=\left(P_{r}\right)_{\text {in }}-\left(\Delta P_{r}\right)_{b}$

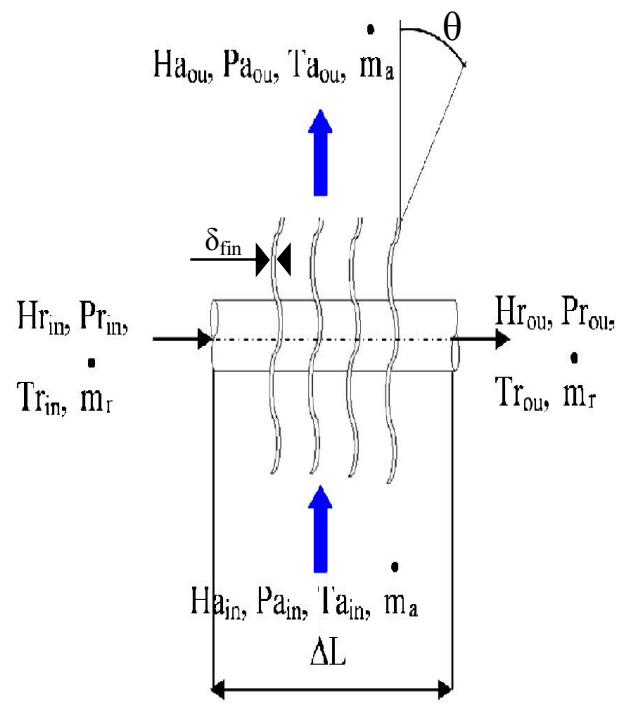

Fig. 1. Control volume element.

For single phase, subcooled liquid and superheated vapour, the Darcy-Weisbach equation is used to calculate the linear pressure drop as:

$\left(\Delta P_{r}\right)_{l}=f \cdot \Delta L \cdot \frac{8 \cdot\left(\dot{m}_{r}\right)^{2}}{\rho_{r} \cdot \pi^{2} \cdot D_{i n}^{5}}$

The friction factor $\mathrm{f}$ is calculated by using the correlation given by Drew et al. (1932).
Pressure losses in bends are calculated by:

$$
\left(\Delta P_{r}\right)_{b}=f_{b} \cdot \frac{8 \cdot\left(\dot{m}_{r}\right)^{2}}{\rho_{r} \cdot \pi^{2} \cdot D_{i n}^{4}}
$$

Where the friction coefficient $\mathrm{f}_{\mathrm{b}}$ is given by Kays et London (1984).

For two phase flow the linear pressure drop is calculated by the equation:

$$
\left(\Delta P_{r}\right)_{l}=\left[\frac{f}{2 \cdot D_{\text {in }}} \Delta L \cdot v_{t p(o u)}+\left(v_{t p(o u)}-v_{t p(i n)}\right)\right] G^{2}
$$

With $\mathrm{G}$ being the mass flow rate per unit area, and $\mathrm{f}$ being the friction factor coefficient determined on the basis of the homogeneous model approach reported by Rohsenow et al. (1998).

Pressure drop calculation in bends for two-phase flow is based on the correlations due to Geary (1975):

$\left(\Delta P_{r}\right)_{b}=\left(f_{b}\right)_{t p} \cdot \frac{L_{b} \cdot x^{2} \cdot G^{2}}{2 \cdot\left(\rho_{r}\right)_{g} \cdot D_{i n}}$

$\mathrm{L}_{\mathrm{b}}$ is the length of the bend, and $\left(\mathrm{f}_{\mathrm{b}}\right)_{\mathrm{tp}}$ is the friction factor for a return bend calculated by:

$\left(f_{b}\right)_{t p}=\frac{80352 \cdot 10^{-8} \cdot \operatorname{Re}_{g}^{0.5}}{\exp \left(0.215 \cdot C_{d} / D_{i n}\right) \cdot x^{1.25}}$

Where $C_{d}$ is the center to center distance of bend, and $\mathrm{Re}_{\mathrm{g}}$ is the Reynolds number based on the gas phase.

\section{1.c. Conservation of Energy}

The equations resulting from the energy balance are summarized as:

$$
\begin{aligned}
& \dot{Q}=\dot{m}_{r} \cdot\left[\left(H_{r}\right)_{\text {ou }}-\left(H_{r}\right)_{\text {in }}\right] \\
& \dot{Q}=\dot{m}_{a} \cdot\left[\left(H_{a}\right)_{\text {in }}-\left(H_{a}\right)_{\text {ou }}\right]
\end{aligned}
$$

and

$\dot{Q}=h_{r} \cdot A_{i n}\left(\overline{T_{w}}-\overline{T_{r}}\right)$

$\dot{Q}=h_{a} \cdot A_{\text {ои }}\left(\overline{T_{a}}-\overline{T_{w}}\right)$

Where:

$\dot{Q}$ is the heat transfer rate, $\mathrm{h}_{\mathrm{r}}$ and $\mathrm{h}_{\mathrm{a}}$ the heat transfer coefficients for the refrigerant and air, respectively.

\section{2 $\mathrm{CO}_{2}$ Side Heat Transfer Coefficient}

For single phase, the heat transfer coefficient $h_{r}$ is calculated using the correlation proposed by Petukhov and Kirillov reported by Kakaç et al. (1998). For two phase flow, the correlations developed by Bennet-Chen and modified by Hwang et al. (1997) have been used to 
calculate $h_{r}$. This is based on the superposition principle, which consists of assuming that $h_{r}$ is the sum of nucleate boiling coefficient $h_{n b}$ and convection heat transfer coefficient $h_{b c}$ as:

$h_{r}=h_{n b}+h_{b c}$

Where $\mathrm{h}_{\mathrm{nb}}$ is given by:

$h_{n b}=\Omega .\left(T_{w}-T_{\text {sat }}\left(P_{l}\right)\right)^{0.4} \cdot\left(P_{\text {sat }}\left(T_{w}\right)-P_{l}\right)^{0.75} \cdot S$

And $\mathrm{h}_{\mathrm{bc}}$ equation is:

$h_{b c}=h_{l} \cdot \operatorname{Pr}^{0.6} \cdot F \cdot(1-x)^{0.8}$

$h_{1}$ is the convective heat transfer coefficient for the liquid phase, calculated by Dittus-Boelter correlation (Incropera et al. 2002). The expressions of $\Omega, \mathrm{S}$ and $\mathrm{F}$ parameters in equations (11) and (12) are given in the appendix A of the present paper.

\subsection{Air Side Heat Transfer Coefficient}

For air flowing over wavy plate-finned tubes, the Wang et al. (2002) correlations for heat transfer and pressure drop are used. Heat transfer is expressed by the Colburn coefficient as:

$J=0.0646 \cdot \operatorname{Re}_{D c}{ }^{{ }^{J}} \cdot\left(\frac{D_{c}}{D_{h}}\right)^{J_{2}} \cdot\left(\frac{F_{s}}{S_{t}}\right)^{-1.03}\left(\frac{S_{1}}{D_{c}}\right)^{0.432} . J_{3}$

and

$$
J=\frac{h_{a} \cdot D_{c}}{k_{a} \cdot \operatorname{Re}_{D c} \cdot \operatorname{Pr}_{a}^{1 / 3}}
$$

$D_{c}$ and $D_{h}$ are the fin collar outside and the hydraulic diameters respectively.

The pressure drop across the coil can be computed by the expression proposed by Kays et London(1984)

$$
\Delta P_{a}=\frac{G_{\max }^{2}}{2 \rho_{a, \text { in }}}\left[f_{a}\left(\frac{A_{c}}{A_{\min }} \cdot \frac{\rho_{a, \text { in }}}{\rho_{m}}\right)+\left(\left(1+\beta^{2}\right)\left(\frac{\rho_{a, \text { in }}}{\rho_{a, \text { ou }}}-1\right)\right)\right]
$$

$\rho_{\mathrm{m}}$ calculated at average temperature of air inlet and outlet.

$A_{c}$ : heat transfer area is the total air side area which contribute in the air-refrigerant heat exchange.

$A_{\text {min }}$ : minimum free flow area is the area which one the air pass throughout the coil.

$\beta$ : ratio of free-flow to frontal area (Kays et London, 1984).

The air friction factor $\mathrm{f}_{\mathrm{a}}$ is calculated by the correlation proposed by Wang et Chi (2000)

$$
f_{a}=0.228 \operatorname{Re}_{D c}^{f l} \cdot(\tan \theta)^{f 2}\left(\frac{F_{s}}{S_{1}}\right)^{f 3}\left(\frac{S_{1}}{D_{c}}\right)^{f 4} \cdot f_{5}
$$

Air properties are calculated using the standard psychometric relations (ASHRAE, 1993).

The expressions of $\mathrm{J}_{1}, \mathrm{~J}_{2}, \mathrm{f}_{1}, \mathrm{f}_{2}, \mathrm{f}_{3}, \mathrm{f}_{4}$ and $\mathrm{f}_{5}$ are given in the appendix $\mathrm{B}$ and $\mathrm{C}$ of the present paper.

The effectiveness-NTU method is selected for heat exchanger thermal calculations using the following additional equations:

$$
\begin{aligned}
& \dot{Q}=\dot{Q}_{\max } \cdot \varepsilon \\
& \dot{Q}_{\max }=C_{\min } \cdot\left(\bar{T}_{a}-\bar{T}_{r}\right)_{i n}
\end{aligned}
$$

The effectiveness $\varepsilon$ expressions related to one phase and two phases flow are respectively:

For single phase:

$\varepsilon=\frac{1-\exp \left\{-\left(1-C_{r}\right) N T U\right\}}{1-C_{r} \cdot \exp \left\{-\left(1-C_{r}\right) N T U\right\}}$

For two phase:

$\varepsilon=1-\exp (-N T U)$

The rate of frost deposition is expressed as a loss of humidity as water vapour condenses on the cold coil surface.

$m_{f}=m_{d a} \cdot\left(\omega_{\text {in }}-\omega_{\text {ou }}\right) \cdot \Delta t$

The mass of the dry air is expressed as:

$m_{d a}=\frac{\dot{m}_{t} . \Delta t}{1+\omega_{i n}}$

\subsection{Frost Properties}

The frost distribution on the entire control volume is assumed to be uniform, and the frost layer is characterised by average properties.

When the saturated air passes throughout the coil whose surface temperature is below the dew point, the first frost layer appears. The initial conditions for frost height and density on cold surface are important as results are sensitive to their selection (Shokouhmand et al., 2009). Jones and Parker (1975) tested the initial conditions by changing the values of the initial frost thickness and density, they found that the prediction results of the frost growth rate would not be affected significantly if the initial frost thickness value approaches a low value $\left(\sim 2 \times 10^{-2} \mathrm{~mm}\right)$. They also found that as long as the initial value of the frost density is significantly smaller than the frost density during growth, it will not affect the solution for the frost growth rate of densification, the recommended value being $\left(\sim 30 \mathrm{~kg} \cdot \mathrm{m}^{-3}\right)$. Hence, in this work, the initial conditions for the frost temperature, thickness and density are fixed as:

$$
\begin{aligned}
T_{f}^{0} & =T_{w} \\
\delta_{f}^{0} & =2.10^{-5} \mathrm{~m} \\
\rho_{f}^{0} & =30 \mathrm{~kg} / \mathrm{m}^{3}
\end{aligned}
$$

The water vapour transferred, from moist air to the frost surface, increases both the frost density and thickness. This phenomenon can be expressed as:

$$
m_{f}=m_{\delta}+m_{\rho}
$$

The mass flux from the frost density absorbed into frost layer is given by Lee et al. (1997): 


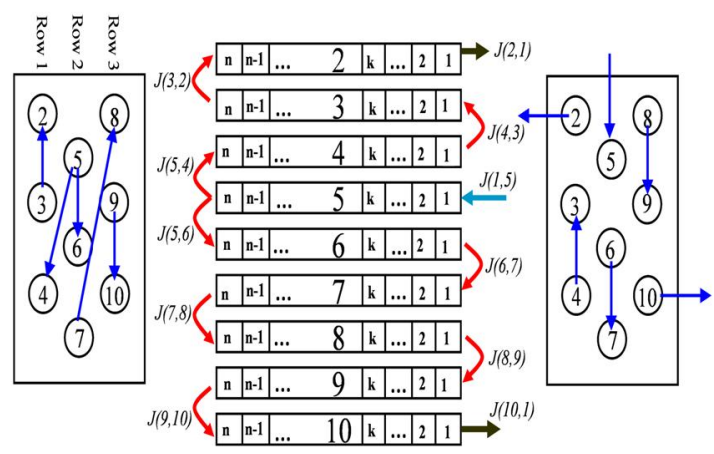

Fig. 2. An example of circuiting configuration and conventions.

$$
\mathrm{m}_{\rho}=\int_{\delta_{\mathrm{f}}=0}^{\delta_{\mathrm{f}}=\mathrm{Y}_{\mathrm{f}}} \alpha_{\mathrm{f}} \rho_{\mathrm{w}} \cdot \Delta \mathrm{t} \cdot \mathrm{d} \delta_{\mathrm{f}}
$$

Were $\alpha_{\mathrm{f}}$ represents an absorption coefficient calculated by:

$$
\alpha_{\mathrm{f}}=\mathrm{D}_{\mathrm{v}} \cdot\left[\frac{\cosh ^{-1}}{\delta_{\mathrm{f}}}\left\{\frac{\rho_{\mathrm{w}, \mathrm{sat}}\left(\mathrm{T}_{\mathrm{f}, \mathrm{s}}\right)}{\rho_{\mathrm{w}, \mathrm{sat}}\left(\mathrm{T}_{\mathrm{w}}\right)}\right\}\right]^{2}
$$

The thermal conductivity, valid

$30 \leq \rho_{f} \leq 400 \mathrm{~kg} \cdot \mathrm{m}^{-3}$, is given by:

$k_{f}=0.132+3 \cdot 13 \cdot 10^{-4} \cdot \rho_{f}+1 \cdot 6 \cdot 10^{-7} \cdot \rho_{f}^{2}$

The diffusion coefficient $\mathrm{D}_{\mathrm{v}}$, valid for $-50 \leq \bar{T}_{a} \leq+20^{\circ} \mathrm{C}$, is given by:

$D_{v}=\left(a+b \bar{T}_{a}+c \bar{T}_{a}^{2}+d \bar{T}_{a}^{3}\right) \cdot 10^{-5}$

With

$$
\begin{array}{ll}
a=2.219928 & c=-0.0000065 \\
b=0.0137779 & d=-5.32937434 .10^{-7}
\end{array}
$$

The frost density and thickness for each time interval are calculated as follow, Kondepudi et al. (1993a):

$\Delta \rho_{f}=\frac{\dot{m} \rho \Delta t}{A_{c, d} \delta_{f}}$

And

$$
\Delta \delta_{f}=\frac{\dot{m}_{\delta} \Delta t}{A_{c, d} \rho_{f}}
$$

$\mathrm{A}_{\mathrm{c}, \mathrm{d}}$ : convective heat transfer area at dry condition.

\section{Resolution Procedure}

This simulation model is intended to cover a large range of operating conditions and handle complex circuiting configurations. In order to achieve this objective, the solution procedure is based on the adoption of an original strategy for the convention of numbering and localizing the tubes, identifying refrigerant entries, exits, tube connections, as well as control volume variables. Rows are counted according to the air flow direction.

$\mathrm{J}(\mathrm{I}, \mathrm{K})$ is a matrix indicating the presence or absence of a junction between two tubes; the coordinates I and K indicate the direction of flow: incoming and destination, respectively. The values of $\mathrm{J}(\mathrm{I}, \mathrm{K})$ are:

$$
J(I, K)=\left\{\begin{array}{l}
0 \quad \text { no connection between } I \text { and } K \text { tubes } \\
1 \quad \text { connection between } I \text { and } K \text { tubes }
\end{array}\right.
$$

Figure 2 shows an example of a heat exchanger with 9 tubes arranged in three rows and three lines with one entrance in tube 5 and two exits in tubes 2 and 10 . $\mathrm{J}(1,5)$ means that the refrigerant enters in tube 5 and exits from tubes 2 and $10 \mathrm{~J}(2,1)$ and $\mathrm{J}(10,1))$. $\mathrm{J}(4,3)$ is the junction between tubes 4 and 3 and the flow comes from tube 4 and goes through tube 3 .

Tubes are numbered starting from 2 at the top and the number one is reserved to external entrance or exit.

For mass flow rate, pressure and temperature variables, the following conventions have been used:

$\mathrm{m}(\mathrm{I}, \mathrm{K})$ is the mass flow rate in the junction $\mathrm{J}(\mathrm{I}, \mathrm{K})$. When $\mathrm{K}=\mathrm{I}, \mathrm{m}(\mathrm{I}, \mathrm{I})$ is the mass flow rate in tube $\mathrm{I}$.

$\mathrm{P}(\mathrm{I}, \mathrm{k})$ is the pressure in the volume control element $\mathrm{k}$ in the tube I.

$\mathrm{T}(\mathrm{I}, \mathrm{k})$ is the temperature in the volume control element $\mathrm{k}$ in the tube $\mathrm{I}$.

Each tube I is divided into $\mathrm{n}$ volume control elements, starting either from the left or from the right, according to the refrigerant flow direction entrance

For this purpose, a parameter DIR(I) having a value of 1 or -1 is allocated to each tube. In Fig. 2, the direction of the upper entrance tube is chosen as a positive reference $(\mathrm{DIR}(\mathrm{I})=1)$,

$\operatorname{DIR}(5)=\operatorname{DIR}(3)=\operatorname{DIR}(7)=\operatorname{DIR}(9)=+1$

$\operatorname{DIR}(2)=\operatorname{DIR}(4)=\operatorname{DIR}(6)=\operatorname{DIR}(8)=\operatorname{DIR}(10)=-1$

The calculation procedure is based on an iterative method consisting for the first step in calculating the hydrodynamic field (mass flow rate and pressure). Then, the conservation equations of mass and momentum are applied to each tube and connection which leads to a total of $3^{*} \mathbf{N T}+\mathbf{N J}$ equations. NT and NJ are the total numbers available of tubes and junctions respectively. In the example shown by Fig. 2 : $\mathbf{N T}=\mathbf{9}$ and $\mathbf{N J}=\mathbf{8}$. This leads to a total number of $3 * \mathbf{9 + 8}=\mathbf{3 5}$ equations.

In general, the total number of the unknown variables is for:

- Mass flow rate $\mathbf{N T}+\mathbf{N J}$ which is $\mathbf{9 + 8}=\mathbf{1 7}$ for the example shown in Fig. 2.

- Pressure $\mathbf{2} * \mathbf{N T}$ which is $\mathbf{2} \boldsymbol{* 9 = 1 8}$ for the example shown in Fig. 2, with the assumption that outlet pressures are equal.

Equations for mass flow rate and pressure are grouped together; the matrix formula is then written as:

$\left[\begin{array}{ll}{\left[A_{m}\right]} & {[0]} \\ {[0]} & {\left[A_{p}\right]}\end{array}\right]\left[\begin{array}{l}(\dot{M}) \\ (P)\end{array}\right]=\left[\begin{array}{l}\left(B_{m}\right) \\ \left(B_{p}(\dot{m})\right)\end{array}\right]$

$\left[A_{m}\right]$ and $\left[A_{p}\right]$ are the matrix coefficients for mass flow rate and pressure. 
$(\dot{M})$ and (P) are the mass flow rate and the pressure vectors.

$\left(\mathrm{B}_{\mathrm{m}}\right)$ and $B_{p}(\dot{m})$ are the second vectors for mass flow rate and pressure, the latter depending on the former. Equation (29) can be written as:

$[A] \cdot(X)=(B(X))$

where $(\mathrm{X})$ is the vector of variables, including pressure and mass flow rate.

The system obtained through the above equation is nonlinear and the Newton-Raphson iterative method based on the calculation of the Jacobian matrix and its inverse is used (Kiusalaas, 2005).

The main steps of the solution procedure are presented by the flow chart represented in Fig. 3.

Once geometric, temporal parameters and inlet thermodynamic data, as well as circuitry configuration parameters are read, the program calculates flow direction and priority vectors DIR(I) and PRIO(I) needed for the organisation of the elements matrix in equation 30, according to the priority of calculation. Using this equation, a preliminary hydrodynamic calculation is performed by the subroutine HYDRO which sets refrigerant mass flow rate and pressure vector $(\mathrm{X})$. The procedure continues by defining the thermodynamic state of refrigerant using subroutine REFPROP, and then the thermal calculation is performed according to the three possible cases:

- Two-phase: calculations are made according to the steps on the right branch of the flowchart.

- Subcooling: is treated according to the steps on the left branch.

- Superheat: no calculations are performed since there is no evaporation.

The elements of the new vectors $(\dot{m})$ and $\left(\mathrm{P}_{\text {new }}\right)$ are calculated using the subroutine HYDRO and the calculation process is repeated until convergence of the refrigerant mass flow rate is reached.

When both hydrodynamic and thermal convergence is obtained, the subroutine HUMI is called to compute the relative humidity in the air inlet and outlet of each volume element. These relative humidities are stored in the matrices $\left[\Phi_{\text {in }}\right]$ and $\left[\Phi_{\text {ou }}\right]$ respectively. The program then checks, for each volume element if the conditions of frost formation are verified, i.e. saturated air and $T_{s}$ below the freezing point. For the elements under the dew point temperature, the subroutine computes the mass of the frost formed and both diffused $\left(\mathrm{m}_{\rho}\right)$ and solidified $\left(\mathrm{m}_{\delta}\right)$ mass parts are calculated. Afterwards, the program calls the subroutine UPCOILGEO to update the geometry configuration of the heat exchanger (tube outer diameter, fin thickness, convective heat transfer area and free flow area) and stores the information in respective matrices. Then, by considering the new geometry of the heat exchanger,

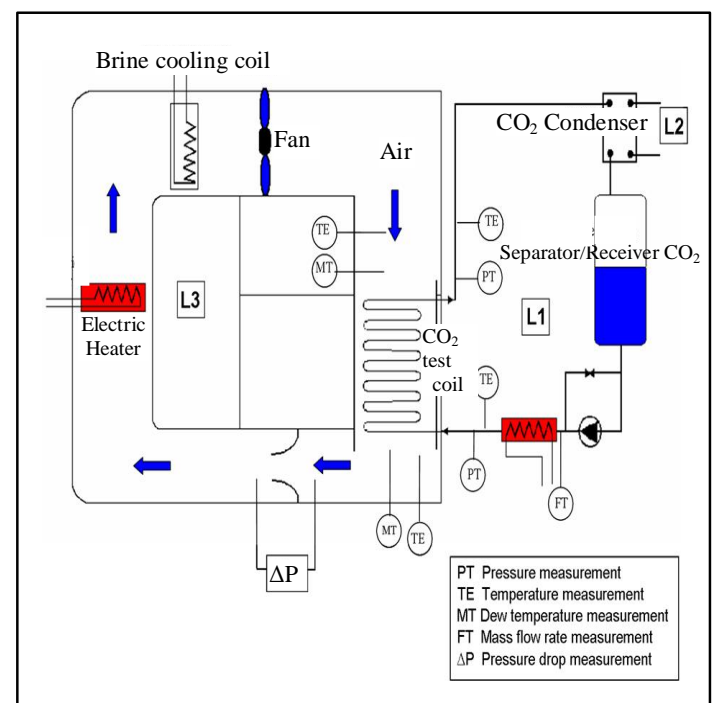

Fig. 4. Schematic diagram of test set-up.

resulting from frost deposition over a time step, the hydrodynamic, thermal and prychrometric calculations process are reapeted for each time step $\Delta \mathrm{t}$ until the total working period of the heat exchanger is covered.

\section{RESUlTS AND COMPARISON WITH REPORTED EXPERIMENTAL DATA}

In order to validate the present model, the results have first been compared with the available information for dry conditions. Preliminary comparisons were performed with numerical results from a previous model developed by Ouzzane et Aidoun (2008) and further validation was achieved by using experimental results from the CanmetENERGY test bench. This experimental set-up shown in Fig. 4, complies with ASHRAE standards (2000a, 2000b) for forced air cooling and

heating coils. Evaporating carbon dioxide is the working fluid in the secondary loop (L1), which includes a $\mathrm{CO}_{2}$ pump, a mass flow meter, a $\mathrm{CO}_{2}$-air coil with aluminum wavy fins and copper tubes, a brazed plate condenser and a reservoir for $\mathrm{CO}_{2}$ condensate. The loop is well instrumented for the purpose of heat and mass transfer balances and fluid flow. For a flexible control of temperature and capacity, a brine loop (L2) was used to cool down the $\mathrm{CO}_{2}$ condenser. The temperature control of this loop is achieved by a mechanical refrigeration system (L3). Loop (L1) is located in a closed room with two compartments corresponding to inlet and outlet of the coil: air flows from one compartment to the other through a duct enclosing the coil. Air circulation is maintained by a blower. The compartments are well insulated in order to reduce infiltration from outside air and moisture. More details on the experimental set up may be found in Aidoun et Ouzzane (2009). The accuracy of the temperature was within $0.05{ }^{\circ} \mathrm{C}$, absolute pressure was read within $\pm 0.3 \mathrm{kPa}$, the pressure differential at the coil within $\pm 5 \mathrm{~Pa}$, and air flow rates within $2 \%$. Experiments were conducted with $\mathrm{CO}_{2}$ inlet temperatures and mass flow rates in the ranges of -35 ${ }^{\circ} \mathrm{C}$ to $-15{ }^{\circ} \mathrm{C}$ and $0.014 \mathrm{~kg} / \mathrm{s}$ to $0.044 \mathrm{~kg} / \mathrm{s}$, air temperatures and approach velocities in the ranges of $-30{ }^{\circ} \mathrm{C}$ to $-9{ }^{\circ} \mathrm{C}$ and $1 \mathrm{~m} / \mathrm{s}$ to $3 \mathrm{~m} / \mathrm{s}$ respectively. 
A.L. Bendaoud et al. / JAFM, Vol. 4, Special Issue, pp. 9-20, 2011.

Table1. Input conditions for validation.

\begin{tabular}{|c|c|c|c|c|c|c|}
\hline & \multicolumn{2}{|c|}{$\begin{array}{c}\text { Mass flow rate } \\
(\mathbf{k g} / \mathbf{s})\end{array}$} & \multicolumn{2}{|c|}{$\begin{array}{c}\text { Inlet } \\
\text { temperature } \\
(\mathbf{C})\end{array}$} & \multicolumn{2}{c|}{$\begin{array}{c}\text { Inlet pressure } \\
(\mathbf{k P a})\end{array}$} \\
\cline { 2 - 7 } & $\mathrm{Air}$ & $\mathbf{C O}_{\mathbf{2}}$ & $\mathrm{Air}$ & $\mathbf{C O}_{2}$ & Air & $\mathbf{C O}_{2}$ \\
\hline Case 1 & 0.5865 & 0.027 & -15.5 & -26.07 & 101.325 & 1624.7 \\
\hline Case 2 & 0.6070 & 0.019 & -15.6 & -26.93 & 101.325 & 1580.5 \\
\hline Case 3 & 0.6090 & 0.015 & -20.3 & -24.03 & 101.325 & 1732.8 \\
\hline Case 4 & 0.5997 & 0.044 & -10.1 & -23.05 & 101.325 & 1787.5 \\
\hline Case 5 & 0.6063 & 0.032 & -21.84 & -25.91 & 101.325 & 1632.0 \\
\hline
\end{tabular}

Table 2. Comparisons of results with numerical results from previous model and with an experimental data.

\begin{tabular}{|c|c|c|c|c|c|c|c|c|}
\hline & & \multicolumn{2}{|c|}{$\begin{array}{l}\text { Capacity } \\
\text { (W) }\end{array}$} & \multirow{2}{*}{$\begin{array}{c}\text { Outlet quality } \\
\mathrm{CO}_{2}\end{array}$} & \multirow{2}{*}{$\begin{array}{c}\begin{array}{c}\Delta \mathbf{P} \\
(\mathrm{kPa})\end{array} \\
\mathrm{CO}_{2}\end{array}$} & \multicolumn{2}{|c|}{$\begin{array}{l}\text { Outlet temperature } \\
\left({ }^{\circ} \mathrm{C}\right)\end{array}$} & \multirow{2}{*}{$\begin{array}{c}\begin{array}{c}\text { Outlet relative } \\
\text { humidity } \\
(\%)\end{array} \\
\text { Air }\end{array}$} \\
\hline & & Air & $\mathrm{CO}_{2}$ & & & Air & $\mathrm{CO}_{2}$ & \\
\hline \multirow{3}{*}{ CASE 1} & Present model & 4091.0 & 4112.9 & $52.8 \%$ & 170.2 & -22.4 & -29.4 & - \\
\hline & Previous model & 4438.3 & 4530.6 & $58.0 \%$ & 195.2 & -23.0 & -29.9 & - \\
\hline & Experiments & 4083.3 & - & $51.4 \%$ & 171.6 & -22.4 & -29.6 & 66.0 \\
\hline \multirow{3}{*}{ CASE 2} & Present model & 4444.6 & 4435.2 & $80.7 \%$ & 152.5 & -22.9 & -30.0 & - \\
\hline & Previous model & 4811.5 & 4914.1 & $89.0 \%$ & 149.6 & -23.5 & -29.9 & - \\
\hline & Experiments & 4471.0 & - & $75.0 \%$ & 132.2 & -22.9 & -29.6 & 65.6 \\
\hline \multirow{3}{*}{ CASE 3} & Present model & 1402.4 & 1379.1 & $32.5 \%$ & 29.3 & -22.6 & -24.5 & - \\
\hline & Previous model & 1557.2 & 1550.0 & $36.5 \%$ & 38.6 & -22.8 & -24.8 & - \\
\hline & Experiments & 1495.9 & - & $35.5 \%$ & 44.4 & -22.7 & -24.9 & 76.0 \\
\hline \multirow{3}{*}{ CASE 4} & Present model & 5588.8 & 5590.6 & $45.3 \%$ & 195.0 & -19.4 & -26.6 & - \\
\hline & Previous model & 5869.4 & 5683.8 & $47.5 \%$ & 398.9 & -19.8 & -30.8 & - \\
\hline & Experiments & 5458.0 & - & $43.5 \%$ & 303.4 & -19.1 & -28.8 & 54.7 \\
\hline \multirow[t]{3}{*}{ CASE 5} & Present model & 1708.4 & 1709.9 & $18.4 \%$ & 42.0 & -24.6 & -26.7 & - \\
\hline & Previous model & 1871.1 & 1798.4 & $20.0 \%$ & 107.7 & -24.9 & -28.0 & - \\
\hline & \begin{tabular}{|l|} 
Experiments \\
\end{tabular} & 1640.0 & - & $18.3 \%$ & 97.0 & -24.5 & -27.8 & 81.5 \\
\hline
\end{tabular}

Table 3. Coil specification and operating condition (Kondepudi et O'Neal, 1993a, 1993b)

\begin{tabular}{|l|l|}
\hline Description & Value \\
\hline Weidth $(\mathrm{m})$ & 0.4572 \\
\hline Height $(\mathrm{m})$ & 0.4572 \\
\hline Depth $(\mathrm{m})$ & 0.022 \\
\hline Fin density (fins/meter) & 710 \\
\hline Fin thickness $(\mathrm{mm})$ & 0.12 \\
\hline Fin type & Flat, aluminium \\
\hline Inner diameter $(\mathrm{mm})$ & 9.195, copper \\
\hline Outer diameter $(\mathrm{mm})$ & 9.525 \\
\hline Number of rows & 1 \\
\hline Number of tubes par row & 18 \\
\hline$\left(\mathrm{T}_{\text {air }}\right.$ in $\quad\left({ }^{\circ} \mathrm{C}\right)$ & 0.0 \\
\hline$\Phi_{\text {in }}(\%)$ & 80.0 \\
\hline Face velocity $(\mathrm{m} / \mathrm{s})$ & 0.762 \\
\hline$\dot{m}_{r} \quad(1 /$ min $)$ & 24.61 \\
\hline Refrigerant type & $50 \%$ ethylene glycol /water \\
\hline$\left(\mathrm{T}_{\mathrm{r}}\right)_{\text {in }} \quad\left({ }^{\circ} \mathrm{C}\right)$ & -15.0 \\
\hline
\end{tabular}

For comparison purposes, five different experimental cases were selected, with their operating conditions sumarized in Table 1.

For all the five cases, presented in this table, the refrigerant is entering the coil in a saturated state with an assumed quality of $0 \%$. The results in Table 2 , show that the coil capacity predicted by the present model is in good agreement with the experimental data, the maximum discrepancy being less than $6.5 \%$. Comparison with the previous model, due to Ouzzane et Aidoun (2008) shows differences of up to $14 \%$. The results show also that the refrigerant pressure drop predicted by the present model is in good agreement with the experimental data except for the fifth case where the discrepancy between predictions and experiments is equal to $57 \%$. Among possible reasons are the cumulative errors resulting from the iterative process applied with correlations for pressure drop whose overall uncertainty is in the range $\pm 67 \%$ (Rin et al., 2006) while for heat transfer coefficient this 
uncertainty on the predictions is within $\pm 40 \%$ range (Hwang et al., 1997). In the analysis performed by Ouzzane et Aidoun (2008), the pressure drop for saturated refrigerant flow is strongly affected by the quality of the refrigerant. Since the iterative process in the present approach is based on tube length increments, and because quality is a computation result, it is possible that sudden jumps in quality occur towards the end of the evaporation process and result in correspondingly high departures of the pressure drop

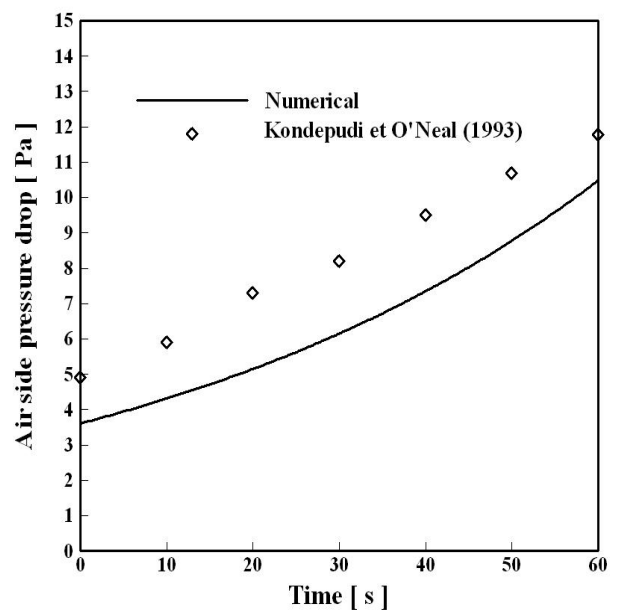

Fig.5. Variation of air side pressure drop across the coil

outside the range covered by the correlations used.

For the frosting case, simulations are conducted according to the test conditions of Kondepudi et O'Neal (1993b). The geometric specifications of the heat exchanger and the operational conditions are summarised in Table 3. In the experimental results shown in Fig. 5, the air side pressure drop increases with time. The increasing trend is due to the frost height continuing to grow, thus reducing

the flow passage cross-sectional area which decreases by nearly $65 \%$, inducing an increase of both the air Reynolds number and the friction factor. Experimental values for pressure drop increase from 4.9 $\mathrm{Pa}$ to 10.77 $\mathrm{Pa}$ at the end of the experiment. The present model predicts the experimental results fairly well.

In the results shown in Fig. 6, the total mass of frost formed in the heat exchanger increases with time. The numerical results show that the part of the condensed water diffused in the frost layer increases the frost density, reaching a value of $496 \mathrm{~kg} \cdot \mathrm{m}^{-3}$. This density corresponds to $0.326 \mathrm{~W} \cdot \mathrm{K}^{-1} \cdot \mathrm{m}^{-1}$ for the thermal conductivity of the frost.

\section{TYPICAL REFRIGERATION APPLICATION}

An example of simulation at low temperature was performed on a wavy fin-and-tube heat exchanger typically used in supermarket applications Fig.7. The rows of the coil are disposed in staggred configuration and the air and refrigerant are flowing in counter-flow.

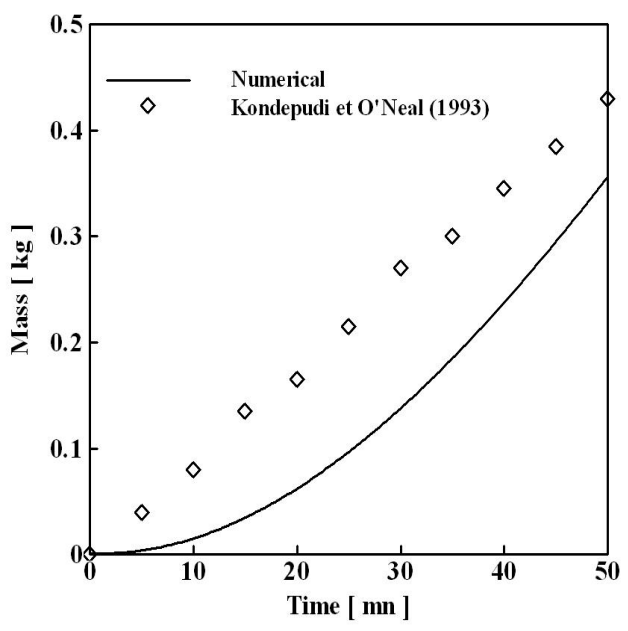

Fig.6. Frost mass accumulation comparison.

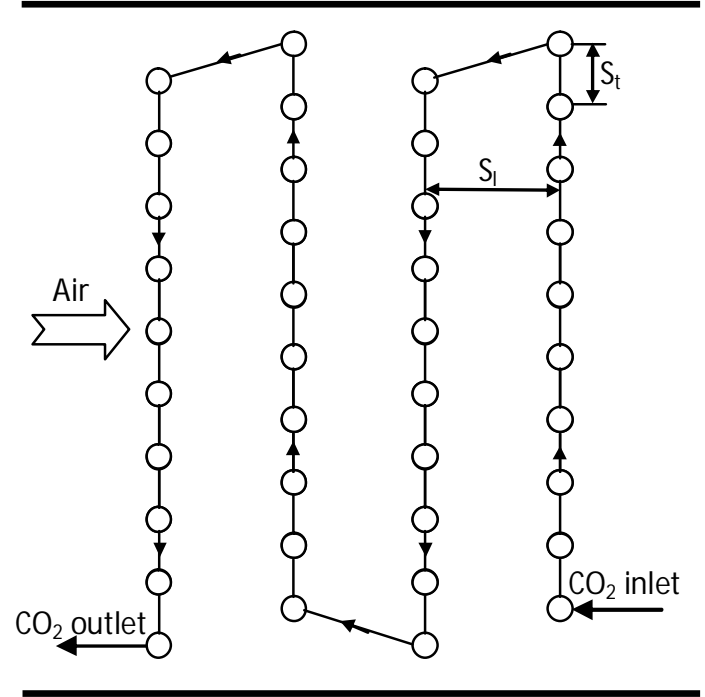

Fig. 7. $\mathrm{CO}_{2}$ circuit of the heat exchanger.

Table 4. Geometrical data and operational conditions.

\begin{tabular}{|l|l|}
\hline Description & Value \\
\hline Configuration & Staggred \\
\hline Refrigerant type & $\mathrm{CO}_{2}$ \\
\hline Number of tubes per row & 10 \\
\hline Numer of tubes row & 4 \\
\hline $\mathrm{S}_{\mathrm{t}}(\mathrm{mm})$ & 31.8 \\
\hline $\mathrm{S}_{1}(\mathrm{~mm})$ & 27.8 \\
\hline Fin thickness $(\mathrm{mm})$ & 0.19 , aluminium \\
\hline Tube length $(\mathrm{m})$ & 0.61, copper \\
\hline Tube inner diameter $(\mathrm{mm})$ & 9.525 \\
\hline Tube outer diameter $(\mathrm{mm})$ & 12.7 \\
\hline Fin density $($ fins $/$ meter $)$ & 70 \\
\hline Inlet relative humidity $(\%)$ & 90 \\
\hline$\left(\mathrm{T}_{\text {air }}\right)_{\text {in }}\left({ }^{\circ} \mathrm{C}\right)$ & -15 \\
\hline Air flow rate $\left(\mathrm{kg} \cdot \mathrm{s}^{-1}\right)$ & 0.6 \\
\hline$\left(\mathrm{T}_{\mathrm{r}}\right)_{\text {in }}\left({ }^{\circ} \mathrm{C}\right)$ & -25 \\
\hline $\mathrm{CO}_{2}$ flow rate $\left(\mathrm{kg} . \mathrm{s}^{-1}\right)$ & 0.03 \\
\hline Fin type & Wavy \\
\hline $\mathrm{Corrugation}$ angle $\left({ }^{\circ}\right)$ & 8 \\
\hline
\end{tabular}


The geometry, core dimensions and relevant operating conditions are summarized in Table 4, were realistic values taken from a manufacturer's specifications manual. Profiles of refrigeration capacity, frost growth, convective heat transfer area, free flow area, air pressure drop and $\mathrm{CO}_{2}$ temperature distribution are presented in Figs. 8, 9, 10, 11, 12 and 13 respectively.

Figure 8 is the variation of the refrigeration capacity delivered by the coil, showing that the capacity decreases, due to frost accumulation on the coil. This is explained by the fact that a thicker frost layer on heat exchanger surface leads to a greatly reduced heat transfer area and increased resistance to heat transfer. This results in a greater reduction of the heat transfer coefficient and of total heat transfer.

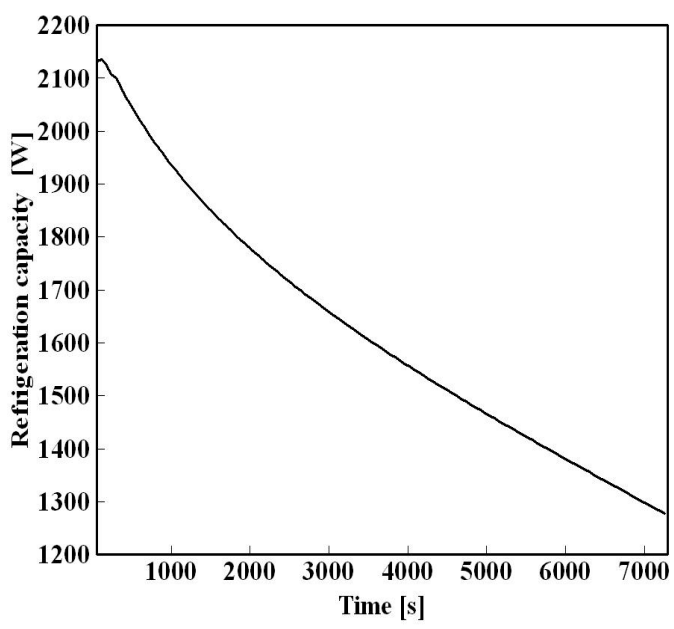

Fig.8. Variation of the refrigeration capacity.

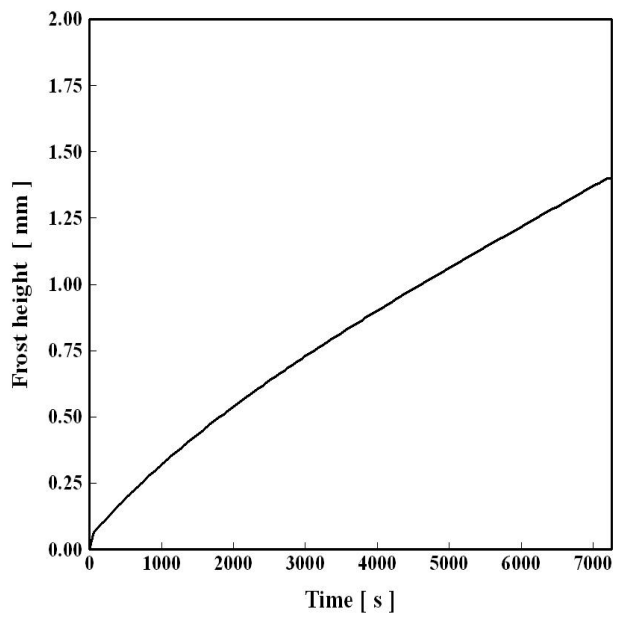

Fig.9. Frost accumulation

Figure 9 shows the variation of the mean frost height formed over the coil. The mean frost height is calculated from the frost deposited on the entire tube rows of the heat exchanger. At $\mathrm{t}=2400 \mathrm{~s}(40 \mathrm{mn})$, the mean frost height reached $50 \%(0.6179 \mathrm{~mm})$ of its final value attained at $\mathrm{t}=120 \mathrm{mn}$ (end of the process). This phenomenon is explained by the fact that at the start of the process (dry case) the heat exchanger delivers a maximum refrigeration capacity thereby producing correspondingly high quantities frost.

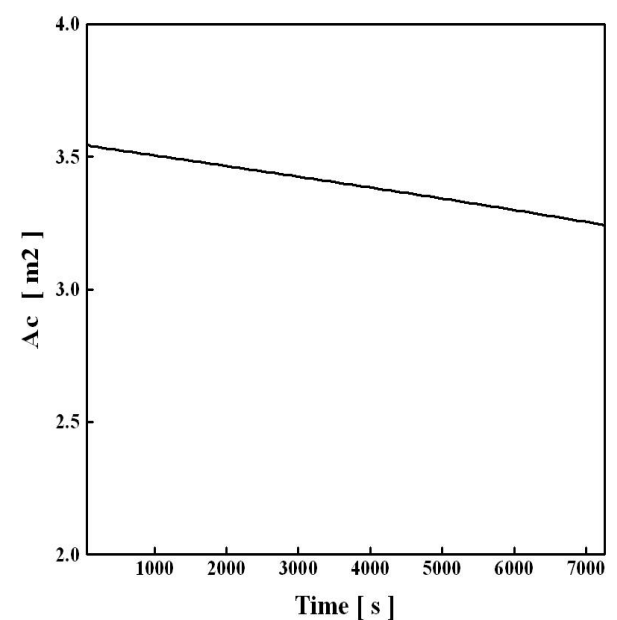

Fig.10. Variation of the total convective heat transfer area.

In proportion, as frost accumulates on the airside heat transfer surface, thermal resistance increases, reducing the refrigeration capacity delivered and slowing down frost deposition. Figure 10 shows the variation of the total convective heat transfer area $\left(\mathrm{A}_{\mathrm{c}}\right)$. The total convective heat transfer area represents the total air side area which contributes to the air- $\mathrm{CO}_{2}$ heat exchange. At the end of the process, the convective heat transfer area is reduced by $9 \%$ if compared to the convective heat transfer area for the dry condition. This variation is due to the fact that frost formation on the tubes and fins increases external diameters, reducing the convective fin area and simultaneously increases fin thickness, thereby reducing the convective heat transfer area of the tubes.

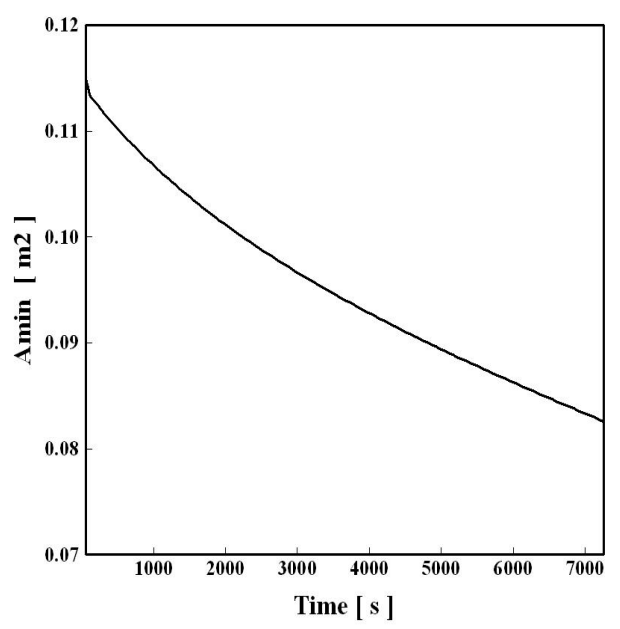

Fig.11. Variation of the mean minimum free flow area.

Figure 11 shows the variation of the mean free flow area $\left(\mathrm{A}_{\text {free }}\right)$ calculated from the total free flow area of the tube rows. The maximum and minimum values of the mean free flow area corresponds to the dry and frosted (at the end of the process) cases respectively. This variation is the result of the frost accumulation on 
the air side area of the heat exchanger. This accumulation enhance the fin thickness and the outer tube diameter which reduce the air section flowing. In the treated example, $\mathrm{A}_{\text {free }}$ is reduced by $28 \%$ at the end of the process.

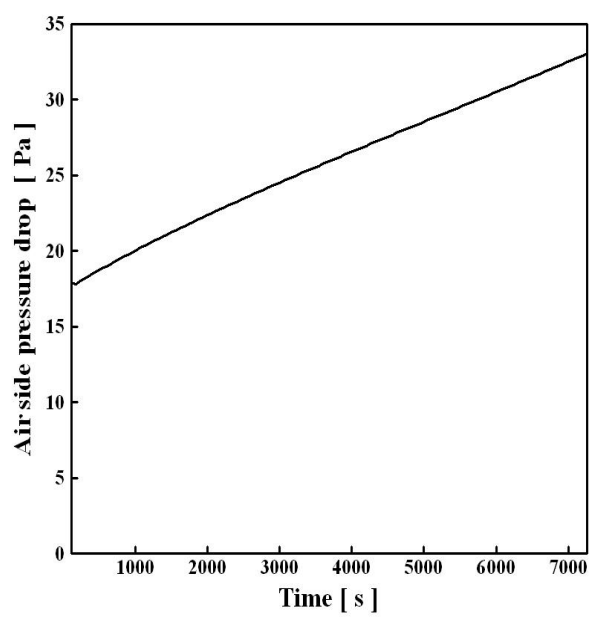

Fig.12. Variation of air pressure drop.

Figure 12 shows the variation of the air pressure drop across the coil. Pressure drop is shown to increase due to frost formation in the coil which adds a supplementary heat transfer resistance and decreases both the convective heat transfer area and the free flow area. The variations of these two areas affect strongly the air pressure drop and overall heat transfer as shown in Fig.13 and discussed in the next section. In the equation (14), used to compute $\Delta \mathrm{P}_{\mathrm{a}}$ across the coil (Kays et London, 1984), both the core friction and contraction effect parts are dependant to the variation of the ratio $A_{c}$ to $A_{\text {free }}$. The variation of this ratio by the accumulation of the frost in the coil increases rapidly the air pressure drop.

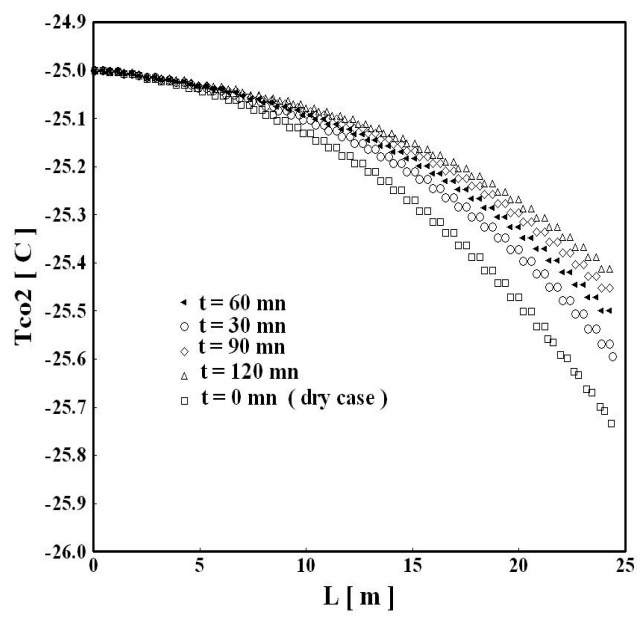

Fig.13. Variation of the $\mathrm{CO}_{2}$ temperature at several periods.

The heat exchanger studied has one refrigerant circuit arranged in four rows and 40 tubes with a total length ' $\mathrm{L}$ ' of $24.4 \mathrm{~m}$. The refrigerant temperature at inlet is -25
${ }^{\circ} \mathrm{C}$, and Figure 13 shows the refrigerant temperature profile over the coil at different time steps: $\mathrm{t}=0 \mathrm{mn}$ (dry case), $30 \mathrm{mn}, 60 \mathrm{mn}, 90 \mathrm{mn}$ and $120 \mathrm{mn}$. The $\mathrm{CO}_{2}$ temperature difference between the inlet and the outlet of the coil represents the temperature glide corresponding to the pressure drop when phase change is taking place. The higher temperature glide corresponds to the dry case performance when the maximum refrigeration capacity is delivered and the higher refrigerant quality at the exit is obtained relate to heat exchanger area. As shown by Aidoun et Ouzzane (2009) the increasing quality of the refrigerant flow as it evolves through the circuit, affect strongly its pressure drop. When frost formation occurs, the coil refrigeration capacity and the exit refrigerant quality both decrease, due to less heat transfer which eventually results in reduced refrigerant pressure drop and low temperature glide.

\section{CONCLUSION}

A mathematical model was developed to calculate the quasi-permanent hydrodynamic and thermal characteristics of circuited, fin-and-tube refrigeration heat exchangers, working under dry (i.e. without condensation) and frosting conditions. Validation for dry conditions was performed with experimental data obtained on a refrigeration facility in Canmet Energy, Varennes, and for frosted conditions, the data used were obtained from the literature. Comparison of numerical predictions and experimental results were shown to be in very good agreement. Simulations based on this model, can therefore be performed to study heat exchanger operation and performance, with complex circuit configurations and different refrigerant flow paths. Preliminary results obtained on a typical supermarket coil show that the frost formation degrades the performance of the heat exchanger by reducing the air-refrigerant heat transfer and by increasing the airside pressure drop. It is intended in future work, to fully use the flexibility offered by this tool to generate results under different condensation and frosting conditions, with geometric configurations, circuit arrangement and refrigerant flow path selection as parameters for optimal geometry and performance selection.

\section{REFERENCES}

Aidoun Z. and Ouzzane M. (2009). A model application to study circuiting and operation in $\mathrm{CO}_{2}$ refrigeration coils, Applied Thermal Engineering vol. 29 , pp. $2544-2553$.

ASHRAE Standard (2000a). Standard methods for laboratory measurement, vol.41.2-1987(RA 92).

ASHRAE (1993). ASHRAE handbook of fundamentals, SI Edition, ch. 6, pp.1-17, Atlanta, Georgia, U.S.A.

ASHRAE Standard (2000b). Methods of testing forced circulation air cooling and air heating coils, $\mathrm{p}$. 33-78.

Bendaoud A.L., Ouzzane M., Aidoun Z. and Galanis N. (27, 28, 29 Mars 2009). Nouvelle approche pour l'étude des évaporateurs de type : tube à ailettes 
air/ $\mathrm{co}_{2}$ à basse température, Proceeding des $14^{\text {emes }}$ Journées Internationales de Thermique (JITH), papier No 18, Djerba, Tunisie.

Corberan J.M. and Melon M.G (1998). A modeling of plate finned tube evaporators and condensers working with R134A, Int. J. of refrigeration vol. 21, No.4 ,pp. 273-283.

Drew T.B., Koo E.C. and Mc Adams W.H. (1932). The friction factors for clean round pipes, Trans. AIChE vol. 28-56.

Geary D.F. (1975). Return bend pressure drop in refrigeration systems, ASHRAE Transactions, vol. 81 , No. 1 , pp. $250-264$.

Incropera F.P. and DeWitt D.P. (2002). Fundamentals of heat and mass transfer, John Wiley and Sons, $5^{\text {th }}$ edition, NY.

Hwang Y., Kim B.H. and Radermacher R. (Nov. 1997). Boiling heat transfer correlation for carbon dioxide, IIR international conference, Heat Transfer Issues in Natural Refrigeration.

Jiang H., Aute V. and Radermacher R. (2006). CoilDesigner: A general-purpose simulation and design tool for air-to-refrigerant heat exchangers, Int. J. of refrigeration vol. 29, pp. 601-610.

Jones and Parker J.D. (1975). Frost formation with varying environmental parameters. J. Heat Transfer vol. 97, pp. 255-259.

Kakaç S., Liu H. (1998). Heat exchangers, Selection, Rating and Thermal Design, CRC Press LLC.

Kays, W.M. and London, A.L. (1984). Compact heat exchangers, 3rd ed., NewYork, McGraw-Hill.

Kiusalaas J. (2005). Numerical methods in engineering with python, CAMBRIDGE University Press, pp.159.

Kondepudi S.N., O'Neal D.L. (1993a). Performance of finned-tube heat exchangers under frosting conditions: I. Simulation model, Int.J. Refrigeration vol. 16, No. 3, pp. 175-180.

Kondepudi S.N. and O'Neal D.L. (1993b). Performance of finned-tube heat exchanger under frosting conditions: II. Comparaison of experimental data with model, Int.J. Refrigeration vol. 16, No. 3, pp. 181-184.

Lee K.S., Kim W.S. and Lee T.H. (1997). A one-dimensional model for frost formation on a cold flat surface, Int. J. Heat Mass Transf. vol. 40 No.18, pp. 4359-4365.

Liang S.Y., Wong T.N. and Nathan GK. (2001). Numerical and experimental studies of refrigerant circuitry of evaporators coils, Int. J. of refrigeration vol. 24, pp. 823-833.
Ouzzane M. and Aidoun Z. (2008). A numerical study of a wavy fin and tube $\mathrm{CO} 2$ evaporator coil, Heat transfer engineering vol. 29, No. 12, pp. 1008-1017.

Rin Y., Jae H.H., Yongchan K. (2006). Evaporative heat transfer and pressure drop of R410A in microchannels, International Journal of Refrigeration, vol. 29, pp. 92-100.

Rohsenow, W.M., Hartnett, J.P. and Cho and Y.I. (1998). Handbook of Heat Transfer, Third Edition, Mc Graw Hill, New York, pp. 17.89-17.97.

Seker D., Karatas H. and Egrican N. (2004a). Frost formation on fin-and-tube heat exchangers. Part I-Modeling of frost, formation on fin-and-tube heat exchangers, Int.J. Refrigeration vol.27, No.4, pp.367-374.

Seker D., Karatas H. and Egrican N. (2004b). Frost formation on fin-and-tube heat exchangers. Part II-Experimental investigation of frost formation on fin- and- tube heat exchangers, Int.J. Refrigeration vol.27, No.4, pp. 375-377.

Shokouhmand H., Esmaili E., Veshkini A., Sarabi Y. $\left(1^{\text {st }}\right.$ January 2009). Modeling for predicting frost behavior of a fin-tube heat exchanger with thermal contact resistance, ASHRAE Transactions, pp. 538-551.

Wang, C.C., Hwang, Y.M. and Lin, Y.T. (2002). Empirical correlations for heat transfer and flow friction characteristics of herringbone wavy fin-and-tube heat exchangers, Int. J. of refrigeration, vol. 25, pp.673-680.

\section{APPENDIX A}

Expression to calculate the parameters $\Omega, \mathrm{S}$ and $\mathrm{F}$ of equations (11) and (12)

$\Omega=0.00122\left(\frac{k_{l}^{0.79} \cdot C p_{l}^{0.5} \cdot \rho_{l}^{0.49}}{\sigma^{0.6} \mu_{l}^{0.29} h_{l v}^{0.24} \rho_{v}^{0.24}}\right)$

$S=\frac{1-E X P\left(-F . h_{l} X_{0} / k_{l}\right)}{F \cdot h_{l} X_{0} / k_{l}}$

$X_{0}=0.05\left[\frac{\sigma}{g\left(\rho_{l}-\rho_{v}\right)}\right]^{0.5}$

$F=\left\{\begin{array}{lr}1.0 & \text { if } X_{t t} \geq 10 \\ 2.0\left(0.213+X_{t t}^{-1}\right)^{0.736} & \text { if } \quad X_{t t}<10\end{array}\right.$

$X_{t t}=\left(\frac{1-x}{x}\right)^{0.9}\left(\frac{\rho_{v}}{\rho_{l}}\right)^{0.5}\left(\frac{\mu_{l}}{\mu_{v}}\right)^{0.1}$ 
A.L. Bendaoud et al. / JAFM, Vol. 4, Special Issue, pp. 9-20, 2011.

\section{APPENDIX B}

Expression to calculate the parameters $\mathrm{J}_{1}, \mathrm{~J}_{2}$ and $\mathrm{J}_{3}$ of equation (13)

$J_{1}=\xi_{1}-0.302$ Nrow $^{-0.24} \cdot \xi_{2}$

$J_{2}=\xi_{3}$. Nrow $^{-0.166-1.08 \tan \theta}\left(\frac{F_{s}}{S_{t}}\right)^{-0.174 \ln (0.5 \text { Nrow })}$

$J_{3}=(\tan \theta)^{-0.692}$ Nrow $^{-0.737}$

$\xi_{1}=-0.0545-0.0538 \tan \theta$

$\xi_{2}=\left(\frac{F_{s}}{S_{1}}\right)^{-1.3}\left(\frac{S_{1}}{S_{t}}\right)^{0.379}\left(\frac{S_{1}}{D_{h}}\right)^{-1.35} \tan \theta^{-0.256}$

$\xi_{3}=-1.29\left(\frac{S_{1}}{S_{t}}\right)^{1.77-9.43 \tan \theta}\left(\frac{D_{c}}{D_{h}}\right)^{0.229-1.43 \tan \theta}$

\section{APPENDIX C}

Expression to calculate the parameters $\mathrm{f}_{1}, \mathrm{f}_{2}, \mathrm{f}_{3}, \mathrm{f}_{4}, \mathrm{f}_{5}$ and $\mathrm{f}_{6}$ of equation (14)

$f_{1}=-0.141\left(\frac{F_{s}}{S_{1}}\right)^{0.0512}(\tan \theta)^{-0.472} \cdot f_{6}$

$f_{2}=-0.562\left(\ln \left(\operatorname{Re}_{D c}\right)\right)^{-0.0923}$ Nrow $^{0.013}$

$f_{3}=0.302 \operatorname{Re}_{D c}^{0.03} \cdot\left(\frac{S_{1}}{S_{t}}\right)^{0.026}$

$f_{4}=-0.306+3.63 \tan \theta$

$f_{5}=\left(\frac{D_{c}}{D_{h}}\right)^{0.383}\left(\frac{S_{1}}{S_{t}}\right)^{-0.247}$

$f_{6}=\left(\frac{S_{l}}{S_{t}}\right)^{0.35}\left(\frac{S_{t}}{D_{h}}\right)^{0.449 \tan \theta}$ Nrow $^{-0.049+0.237 \tan \theta}$ 